\title{
Indicadores e quantificação da degradação ambiental em áreas mineradas, Ubatuba (SP)
}

\author{
Cláudio José Ferreira', Maria José Brollo ${ }^{1}$, Marta Eichemberger Ummus ${ }^{1,2}$ \& \\ Tulius Dias Nery ${ }^{1,3}$
}

\begin{abstract}
Resumo A produção de saibro (material argilo-arenoso) em Ubatuba, município do Litoral Norte do Estado de São Paulo, desempenhou papel importante no desenvolvimento municipal, por seu uso na infra-estrutura civil e na manutenção da rede viária. Por ser um bem mineral abundante e não requerer tecnologias sofisticadas para sua produção, seu aproveitamento, ao longo das últimas quatro décadas, deu-se de uma forma desordenada e sem compromisso com a correta finalização da lavra e recuperação ambiental. $O$ trabalho apresenta a definição de quatro indicadores da degradação ambiental devido à extração mineral de saibro e secundariamente rocha ornamental (processos erosivos, irregularidade do terreno, solo exposto e cobertura vegetal) e sua quantificação, obtendo-se um índice numérico de degradação.
\end{abstract}

Palavras-chave: geoindicadores, monitoramento ambiental, geoprocessamento, mineração, análise espacial.

\begin{abstract}
Definition and quantification by gis processing of environmental degratation indicators in mined areas, Ubatuba, state of São Paulo, Brazil. The production of clay-sandy material ("saibro") for use in construction can be considered strategic to the regional development, in the Ubatuba municipality, where the occurrence of mangrove and waterlogged fields require terrain filling before the construction of houses, roads, streets or buildings. Between the late 60's and early 90's intensive exploitation of clay material from residual soil for civil construction took place in this region. Exploitation of large volumes of this material required only very simple technology, which on the other hand has caused highly adverse environmental impacts due mining mismanagement. This paper deals with the definition of land dereliction indicators due mineral exploitation for clay material and dimension stone (mainly the occurrence of erosion processes, terrain irregularities, exposed soil and vegetation cover) and its numerical assessment.
\end{abstract}

Keywords: land dereliction indicators, environmental monitoring, geoprocessing, mineral exploitation, spatial analysis.

INTRODUÇÃO No Litoral Norte do Estado de São Paulo ocorre expressivo desenvolvimento regional, com conseqüentes demandas para o uso dos recursos naturais, de espaços para atividades de turismo e de obras e equipamentos de infra-estrutura. Por outro lado, a região apresenta grande relevância ecológica e para a conservação da biodiversidade com importantes reservas naturais que atingem até $80 \%$ dos cerca de $2.000 \mathrm{~km}^{2}$ que compõem a região. A demanda e a política de desenvolvimento sustentável da área ocorrem em condições ambientais bastante sensíveis, caracterizadas por frágil estabilidade geodinâmica condicionada pelo relevo montanhoso da Serra do Mar e ecodinâmica, onde predominam severas restrições para ocupação territorial e uso dos recursos naturais. A mineração, caracterizada na região, pela exploração de bens de uso direto na construção civil, tais como, areia, saibro, brita, rocha ornamental e rocha para cantaria constitui um dos importantes elementos desta estrutura, por seu caráter modificador das condições ambientais.
No caso de Ubatuba (Fig. 1) a produção de saibro (material argilo-arenoso proveniente do solo de alteração de rochas granítico-gnáissicas da região) foi e ainda pode ser considerada, estratégica ao desenvolvimento municipal, por seu uso na infra-estrutura civil e na manutenção da rede viária. Ainda que seja um bem mineral abundante e não requeira tecnologias sofisticadas para sua produção, seu aproveitamento desordenado e sem compromisso com a correta finalização da lavra, juntamente com a explotação de rocha ornamental ("granito verde Ubatuba"), ocasionou grave degradação ambiental no município, ao longo das últimas quatro décadas (Ferreira et al. 2005). A ação fiscalizadora do poder público a partir da década de 1990 foi capaz de limitar quase que completamente esse tipo de lavra ilegal, porém não conseguiu sucesso na promoção da recuperação ambiental de pelo menos 60 áreas degradadas pela atividade de mineração (Brollo et al. 2005, Ferreira et al. 2006b).

Em Ubatuba foram cadastradas 116 áreas (Fig.

1 - Instituto Geológico, Seção de Geologia Aplicada e Ambiental, Secretaria do Meio Ambiente do Estado de São Paulo, São Paulo (SP), Brasil. E-mails: cjfcjf@gmail.com,mjbrollo@yahoo.com.br,

2 - Instituto Nacional de Pesquisas Espaciais, INPE, São José dos Campos (SP), Brasil. E-mail: martaummus@hotmail.com

3 - Departamento de Geografia, FFLCH, USP, São Paulo (SP), Brasil. E-mail: tuliusdias@yahoo.com.br 


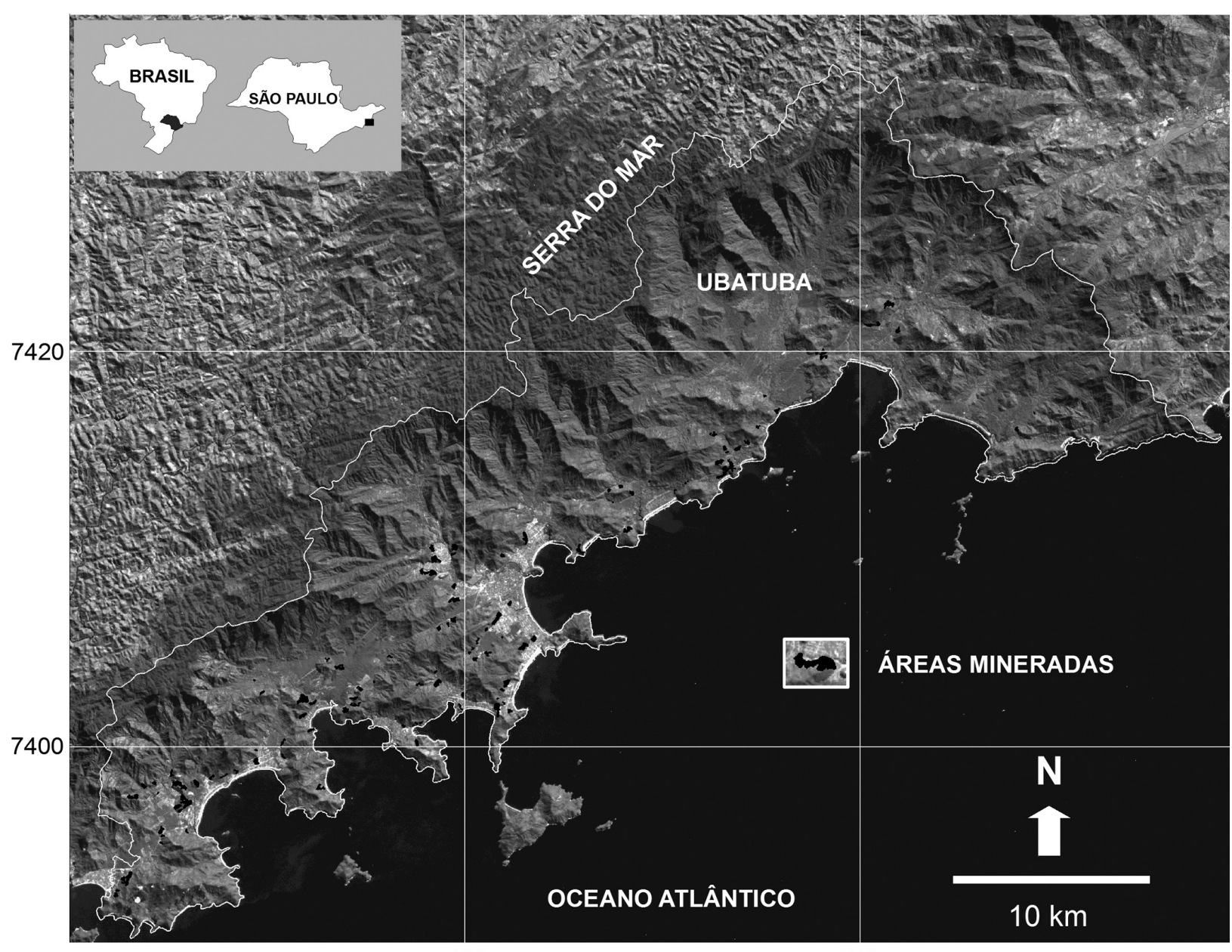

490

510

Figura 1 - Localização do município de Ubatuba no Estado de São Paulo e distribuição das 116 áreas mineradas para saibro elou rocha ornamental (Grades em coordenadas UTM, zona 23, datum SAD69).

1), nas quais foi reconhecida a ocorrência de extração mineral de saibro e rocha ornamental. As áreas são pequenas com dimensão média em torno de $31.000 \mathrm{~m}^{2}$, mas que podem variar de $800 \mathrm{~m}^{2}$ até cerca de $150.000 \mathrm{~m}^{2}$. Apesar das pequenas dimensões, a área total ocupada por essas antigas extrações atinge $3,6 \mathrm{~km}^{2}$, o que representa $0,5 \%$ do território continental de Ubatuba, de $700 \mathrm{~km}^{2}$.

Essas áreas mineradas degradadas depreciam o patrimônio paisagístico desta cidade turística, oferecem perigos à população, aos equipamentos do entorno, ao meio ambiente e provocam estagnação da atividade econômica de mineração no município. Ferreira et al. (2005) apontam como causas imediatas desta situação:

a) a mineração clandestina de saibro, realizada entre as décadas de 1960 e 1990;

b) o insucesso na exigência da recuperação ambiental pelos setores públicos responsáveis, devido à dificuldade na identificação dos responsáveis pela extração e complexidade da divisão de responsabilidades;

c) a morosidade na legalização e obtenção de licenças ambientais e minerárias dos empreendimentos.

As causas acumulativas passam pela falta de estrutura técnica dos setores licenciadores municipais e estaduais; a complexidade do licenciamento ambiental e a função dupla do município que, como principal consumidor do bem mineral, tem igualmente as funções de licenciamento e fiscalização. Tais problemas decorrem ainda de regras que nem sempre enquadraram a mineração de saibro como tal, tendo sido encarada como simples áreas de empréstimo à margem da legislação ambiental e minerária.

De modo amplo, a degradação ambiental ocorre quando há perda de adaptação às características físicas, químicas e biológicas do ambiente, gerando uma área degradada, podendo inviabilizar o seu desenvolvimento sócio-econômico-ambiental (Sánchez 1998; Brollo et al. 2002). Sem o apoio de medidas específicas, o controle dessa degradação, bem como a recuperação do ambiente, torna-se impossível ou ocorre de maneira extremamente lenta, por vezes ampliando ainda mais a área e a intensidade da degradação. Nas áreas degradadas ocorre o uso inadequado dos recursos naturais, bem como desastres naturais, que modificam as condições de potencialidade e fragilidade ambiental. Esta situação desestabiliza a dinâmica do meio ambiente e afeta a qualidade de vida das populações, gerando um impacto ambiental negativo, causado pela destruição, remoção ou exclusão da vegetação nativa e da fauna, pela perda ou remoção da camada 
fértil do solo, pela alteração da qualidade e do regime de vazão do sistema hídrico, pela geração de poluição (hídrica, ambiental, visual, etc.) e contaminação dos recursos naturais (Brollo 2001; Brollo et al. 2002).

A utilização de indicadores para diagnóstico e acompanhamento da realidade de um lugar em seus vários aspectos tem sido uma tendência corrente nos últimos anos. No contexto da sustentabilidade, os indicadores surgem como instrumentos para análise e acompanhamento dos processos de desenvolvimento, servindo não só como subsídio para a formulação de políticas públicas, mas também no monitoramento da execução e dos efeitos dessas políticas (Cunha 2003). Esta tendência também vem ocorrendo no campo das geociências, onde os indicadores assumem um aspecto mais amplo, sendo denominados geoindicadores (Segnestam et al 2000; Campagnoli 2002; Berger et al. 2003; Bitar \& Ceneviva 2003; Fidalgo 2003; Rego Neto 2003; Cendrero et al. 2004; Zuquette et al. 2004; Degiovanni 2005; Diniz et al. 2005). Indicadores são definidos como medidas de alta resolução e curto prazo (inferior a 100 anos) de mudanças dos processos e fenômenos geológicos que ocorrem na superfície da terra ou perto dela e que são significativos para o monitoramento ambiental e sua respectiva avaliação (Berger \& Iams 1996). Como os geoindicadores descrevem os processos do meio físico e sua evolução, pode-se associá-los às diferentes fases da política ambiental, no que tange à identificação de problemas, à formulação de políticas e ao monitoramento do desempenho das políticas ambientais.

OBJETIVOS A pesquisa que deu origem a este artigo teve como objetivos gerais estabelecer diretrizes para a regeneração sócio-ambiental de áreas degradadas por mineração de saibro em Ubatuba, SP. A situação foi investigada considerando-se a necessidade do poder público municipal em recuperar áreas degradadas, em reduzir os riscos a perigos geológicos de pessoas e bens e em articular e promover o ordenamento e racionalização da exploração de saibro no município, compatibilizando-a com outros usos do solo. Isto posto, são objetivos deste trabalho:

a) definir e quantificar indicadores da degradação ambiental devido à exploração mineral de saibro e rocha ornamental em Ubatuba, tendo-se o pressuposto de que indicadores devem ser simples, objetivos, confiáveis e mensuráveis;

b) estabelecer uma metodologia de hierarquização das áreas mineradas quanto à degradação.

AS ÁREAS MINERAdAS EM UBATUBA Ubatuba localiza-se no Litoral Norte do Estado de São Paulo, distando $245 \mathrm{~km}$ da capital (Fig. 1). Apresenta uma área continental de $700 \mathrm{~km}^{2}$, com cerca de $80 \%$ do território situado em área de conservação ambiental, o Parque Estadual da Serra do Mar. A população é de 77.942 habitantes, dos quais $97 \%$ estão em área urbana e 3\% em área rural (IBGE 2006). O turismo é a principal atividade econômica, o que implica para o setor de serviços $78,35 \%$ das riquezas adicionadas ao município, o setor industrial $21,42 \%$ e a agropecuária $0,23 \%$ (SEADE 2006). No contexto geológico regional o município está inserido no Complexo Costeiro e as principais litologias presentes na região são charnoquitos, granitos e gnaisses. No contexto geomorfológico estão presentes Serrania Costeira, Morraria Costeira e Baixadas Litorâneas.

Os estudos mais abrangentes sobre os recursos minerais da região de Ubatuba iniciaram-se na década de 70 (projeto Santos-Iguape, de Silva et al. inédito). Na década de 80 destacou-se a atuação da SUDELPA (Superintendência do Desenvolvimento do Litoral Paulista), por meio dos projetos: "Planejamento minerário na ocupação do solo em área de atuação da SUDELPA" (Chiodi et al. inédito), "Rochas Ornamentais" (Chieregati \& Macedo 1982) e "Subsídios para o planejamento minerário do município de Ubatuba" (Bitar et al. 1985). Na década de 90 destacaram-se: a elaboração de cartas geotécnicas municipais pelo Instituto Geológico e Instituto de Pesquisas Tecnológicas como a "Carta Geotécnica de Ubatuba" (Braga et al. 1991); o trabalho de Bitar (1990); o levantamento das áreas mineradas, executado pela Secretaria do Meio Ambiente para o projeto "Macrozoneamento do Litoral Norte"; e os trabalhos de Silva (1995) e Silva \& Martins (1997).

Os estudos das décadas de 70 e 80 enfocam a atividade de mineração com o viés do aproveitamento econômico (Silva et al. inédito). No levantamento executado por Chiodi et al. inédito já existe uma incipiente preocupação ambiental, com a inclusão de um campo de "Lavra e meio ambiente", porém normalmente classificada como "não interfere".

A visão da atividade de mineração como causadora de impactos ambientais e de perigos geológicos surge a partir do final da década 80 , relacionada à elaboração do relatório sobre a instabilidade da Serra do Mar e situações de risco ("Instabilidade da Serra do Mar no Estado de São Paulo - situações de risco", inédito).Na adoção de suas diretrizes, principalmente na execução de cartas geotécnicas municipais e na implantação do Plano Preventivo de Defesa Civil específico para Escorregamentos nas Encostas da Serra do Mar - PPDC, as áreas de lavras são descritas detalhadamente quanto aos seus impactos ambientais e perigos associados com vistas à avaliação dos riscos, conforme podemos encontrar em Braga et al. (1991), Bitar (1990), Silva (1995) e Silva \& Martins (1997).

Ferreira (2006) com base nos levantamentos anteriores e em dados inéditos uniformiza os dados disponíveis, adequando-os à visão de que o aproveitamento dos bens minerais no Litoral Norte deve, prioritariamente, submeter-se à recuperação ambiental das áreas paralisadas. A abordagem alia ainda, uma avaliação dos perigos geológicos, da vulnerabilidade e do valor dos elementos do entorno (pessoas e bens) às praças de lavra, informação necessária para a análise de risco.

Uma das limitações dos cadastros anteriores é que as áreas foram representadas por pontos, o que limitava bastante a análise da degradação. O presente trabalho apresenta as áreas mineradas na forma de 
polígonos, digitalizados a partir de ortofotos digitais coloridas com resolução de $1 \mathrm{~m}$. A foto-interpretação permitiu ainda identificar novas áreas degradadas pela mineração, anteriormente não cadastradas.

MÉTODO A caracterização e classificação da degradação é uma etapa fundamental para o estabelecimento de diretrizes para a recuperação de áreas degradadas, pois define áreas prioritárias e especifica indicadores dos problemas a serem enfrentados. Partindo das discussões apresentadas em Brollo et al. (2005)e Ferreira et al. $(2006 \mathrm{a}, \mathrm{b})$ buscou-se um detalhamento dos indicadores da degradação e um tratamento numérico que a quantificasse de modo mais apurado.

A quantificação numérica apresenta vantagens, tais como a obtenção de uma classificação contínua (que pode ser dividida em classes, conforme a análise de interesse), clareza na obtenção dos parâmetros (que pode ser realizada por diferentes pessoas e graus de experiência), além de maiores possibilidades de análise dos dados e mudança da importância de cada indicador. A ferramenta utilizada neste processo de análise foi o Sistema de Informação Geográfica SPRING (Câmara et al. 1996), por meio do qual foram delimitadas as áreas mineradas, com base em ortofotos digitais de resolução $1 \mathrm{~m}$, de 2001 (escala nominal de trabalho em torno de 1:3.000).

Para as áreas degradadas por mineração de saibro, foram definidos quatro indicadores de degradação: processos erosivos, irregularidade do terreno, solo exposto e cobertura vegetal herbácea e arbustiva (Figs. 2, 3 e 4). A análise integrada destes indicadores possibilitou a obtenção de um índice de degradação para cada área e sua classificação.

Processos erosivos Em muitas áreas mineradas ocorreu o desenvolvimento de processos erosivos, tais como erosão laminar, sulcos, ravinas e boçorocas. Para a quantificação desse parâmetro foram traçadas na imagem linhas representativas desses processos (Fig. $3 \mathrm{~A}$ ). A diferenciação na dimensão horizontal entre as intensidades dos processos erosivos é razoavelmente contemplada pelo método, pois cada ravina profunda ou boçoroca foi representada por mais de uma feição linear, tanto paralelas, para obtenção da variação lateral do eixo principal da boçoroca ou ravina profunda, como em ângulo, para obtenção de suas ramificações. No entanto, o método apresentado não permitiu a quantificação da intensidade do processo erosivo na sua dimensão vertical, considerando que ele se baseia na interpretação das características espectrais e não tridimensionais da imagem. Além disso, a pesquisa não incluiu extensivos trabalhos de campo com o objetivo de caracterizar parâmetros tais como, profundidade das feições erosivas, nível do lençol freático e erodibilidade do solo, uma vez que na região estudada, os processos de boçorocamento não são críticos (ocorrem apenas em três sítios entre os 116 estudados).

A quantificação do indicador processos erosivos deu-se pela soma dos lineamentos em cada polígono representativo da área minerada. A unidade de medida é o metro linear. Utilizou-se a ferramenta "Operações Métricas", do SPRING, para a obtenção da soma de todos os lineamentos traçados em cada um dos 116 polígonos mapeados. Os resultados foram tabelados um a um para posterior normalização.

Irregularidade do terreno Esse indicador compõese de três parâmetros: as quebras de talude relacionadas à atividade extrativa, a amplitude e a declividade da encosta (Fig. 3B). A atividade de extração de saibro e rocha ocasionou alteração da geometria original do terreno com a formação de taludes regulares ou irregulares, cavidades, buracos, ranhuras, etc. Esses elementos puderam ser discriminados na imagem por traços lineares. A exemplo dos processos erosivos foi feita a soma dos lineamentos de cada polígono da área mine-

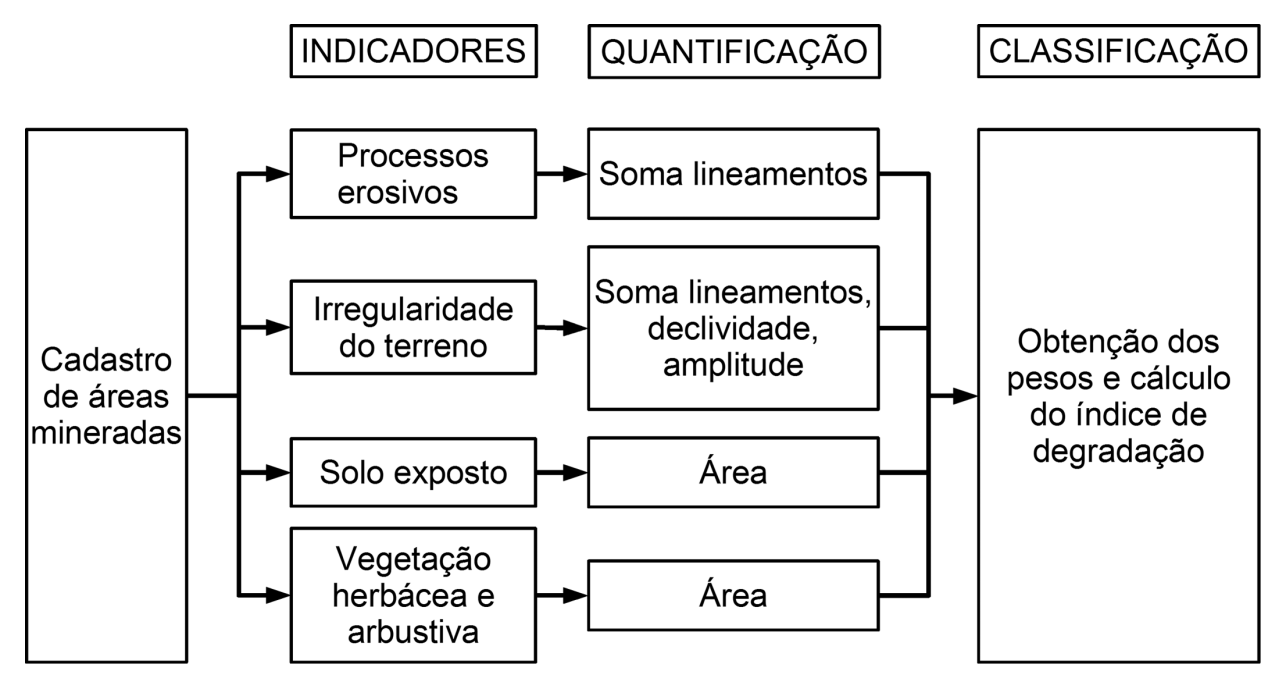

Figura 2 - Fluxograma de obtenção da classificação da degradação por meio do indice de degradação. 

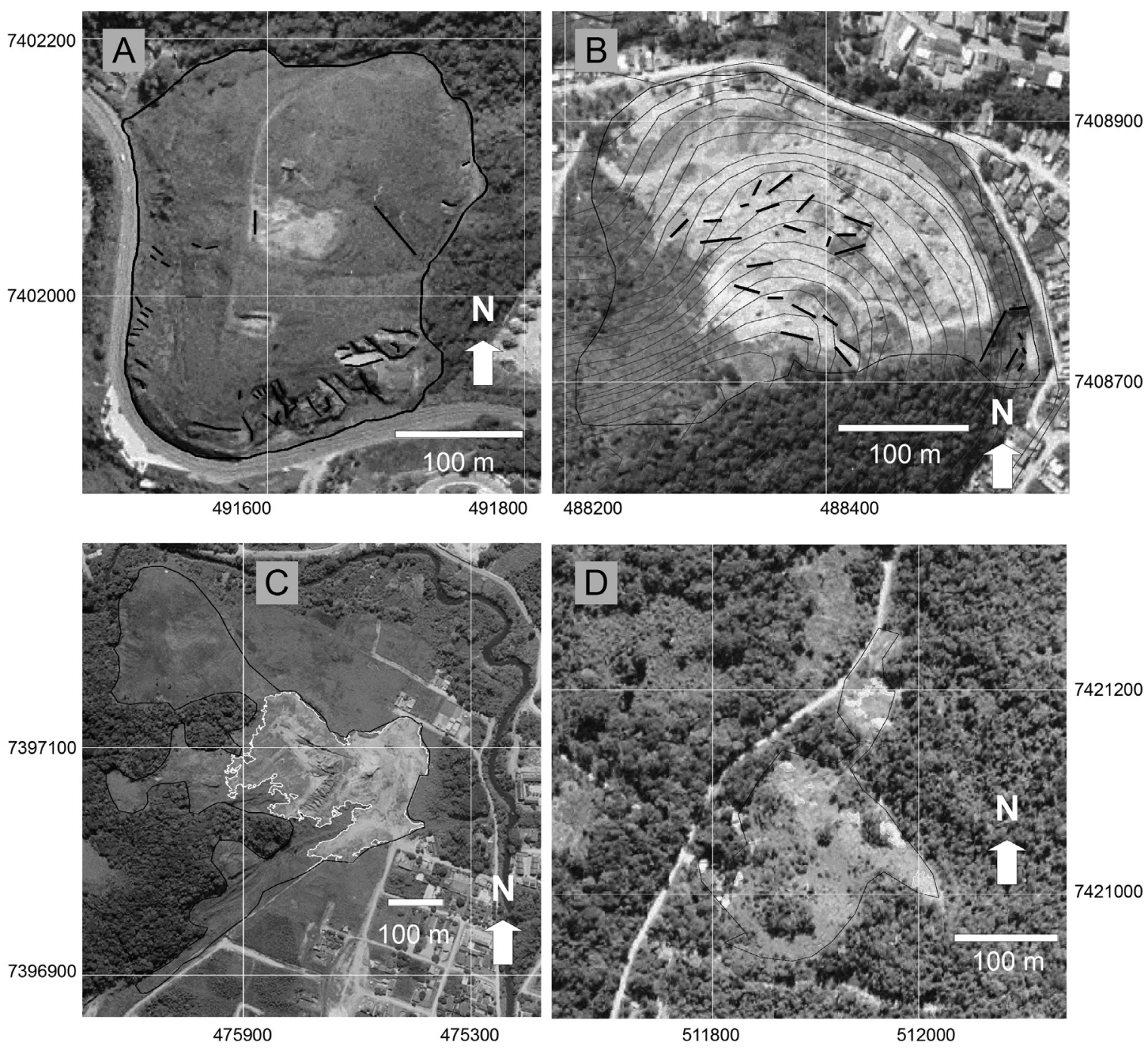

Figura 3 - Exemplos de obtenção dos indicadores. A: traços indicadores de processos erosivos. B: traços indicadores da irregularidade do terreno e curvas de nível, das quais foram obtidas a amplitude e declividade; C: tipos de cobertura: solo exposto (polígono delimitado por linha branca) e vegetação herbácea e arbustiva (polígono delimitado por linha preta); D: tipos de cobertura: vegetação herbácea, arbustiva e localmente até arbórea (polígono delimitado por linha preta) e solo exposto (polígonos delimitados por linhas brancas). Grades em coordenadas UTM, zona 23, datum SAD69.

rada, por meio da ferramenta "Operações Métricas", do SPRING e os resultados tabelados individualmente. Considerou-se que a irregularidade causada pela atividade de mineração pode se acentuar ainda mais, dependendo da amplitude e da declividade da encosta.

Para o cálculo da amplitude de cada polígono representativo dos objetos em análise, gerou-se no SPRING uma grade de cotas altimétricas com base em curvas de nível disponíveis na escala 1:10.000 e 1:50.000. Por meio de algorítmo na linguagem Legal obteve-se os valores das cotas máximas zonais e mínimas zonais, que foram atualizados automaticamente na tabela de dados. Posteriormente, a amplitude foi calculada automaticamente por uma operação de subtração entre as colunas contendo a cota máxima e a cota mínima.
Para o cálculo da declividade média do polígono da área minerada, utilizou-se o mesmo procedimento. Gerou-se no SPRING uma grade de declividade em graus (Fig. 4B) e por meio de uma rotina em Legal calculou-se a média zonal de cada polígono (Fig. 4C). A rotina de programação atualizou automaticamente a tabela de dados.

Os valores obtidos para os três parâmetros foram normalizados para uma escala de 0-1 conforme descrito posteriormente e, finalmente, o índice de irregularidade do terreno foi calculado por meio de uma média aritmética simples, seguida de nova normalização.

Solo exposto Constitui porções do polígono da área minerada sem cobertura vegetal, identificadas e delimitadas na imagem por suas propriedades espectrais mais 
claras (Fig. 3C). A quantificação desse fator dá-se pelo cálculo da área $\left(\mathrm{em} \mathrm{m}^{2}\right)$ dos polígonos de solo exposto. O SPRING calcula automaticamente essa área para cada polígono.

Vegetação herbácea e arbustiva Compõe porções do polígono da área minerada nos quais houve um desmatamento provocado pela atividade extrativa, mas que atualmente apresenta cobertura vegetal em regeneração (Fig. 3D). Sua quantificação é dada pelo cálculo da área $\left(\mathrm{em} \mathrm{m}^{2}\right)$ do polígono com esse tipo de cobertura, calculada automaticamente pelo SPRING.

A foto-interpretação realizada foi complementada com os registros dos trabalhos de campo (fotografias e fichas de descrição). A figura 4A mostra um exemplo de obtenção na imagem dos quatro indicadores anteriormente descritos. Os valores absolutos obtidos para os quatro parâmetros foram normalizados para o inter- valo de [0 a 1] por meio da equação 1:

$\mathrm{Vn}=\frac{(\mathrm{Vf}-\mathrm{Vmin})}{(\mathrm{Vmax}-\mathrm{Vmin})}$

onde, $\mathrm{Vn}=$ valor normalizado; $\mathrm{Vf}=$ valor a ser normalizado; Vmin $=$ valor mínimo $;$ Vmax $=$ valor máximo .

No cálculo do índice de irregularidade do terreno, também foi realizada a mesma normalização entre suas três variáveis, geometria da extração, amplitude e declividade da encosta para se obter um valor médio, o qual foi novamente normalizado.

Considerou-se que os quatro indicadores contribuem de modo e intensidade diferente para a quantificação da degradação. A ocorrência de processos erosivos em uma área foi tratada como o pior caso, seguido da irregularidade do terreno, área de solo exposto e, como caso menos grave, a área de cobertura herbácea e arbustiva.
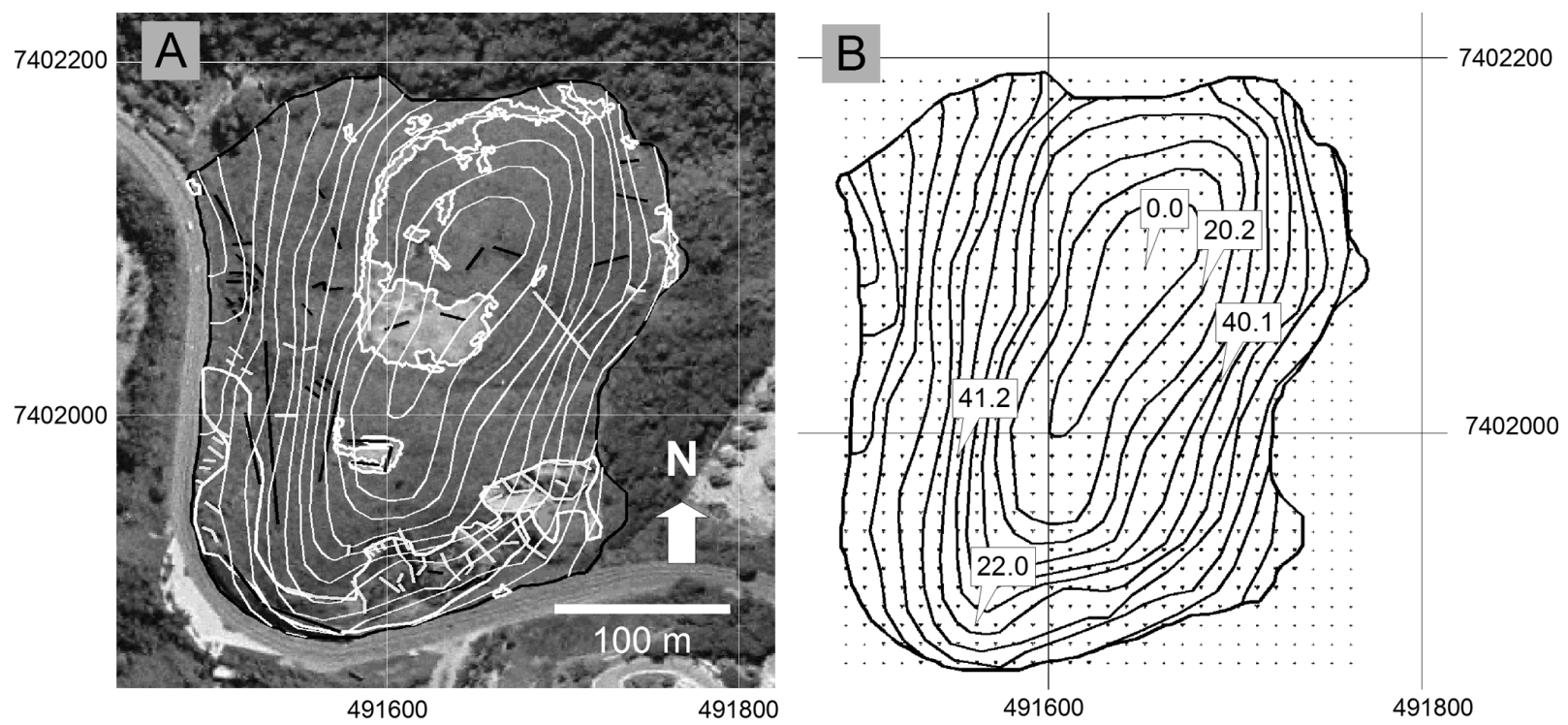

\{

//Programa para atualizar o atributo DECL_MED por meio do operador MEDIA ZONAL

//Declaracao das variaveis

Objeto obj ("nome_tabela_objeto");

Cadastral cad ("nome_categoria_poligonos_areas_mineradas");

Numerico num ("nome_categoria_curvas_nivel");

//Instanciacao

cad = Recupere (Nome = "nome_plano_informacao_poligonos_areas_mineradas");

num $=$ Recupere (Nome = "nome_plano_informacao_grade_declividade_curvas_nivel");

//Atribuicoes

obj. "DECL_MED" = Atualize (num, obj OnMap cad, MedZ);

\}

Figura 4 - Uso do geoprocessamento na quantificação da degradação. A. Discriminação em uma área minerada dos quatro indicadores definidos para a obtenção do indice de degradação: processos erosivos (lineamentos brancos), irregularidade do terreno (lineamentos pretos, amplitude e declividade), áreas com solo exposto (polígono delimitado pelas linhas brancas) e áreas com vegetação arbustiva (polígono delimitado pelas linhas pretas); traços brancos finos - curvas de nível com espaçamento de $5 \mathrm{~m}$. B. Exemplo de grade de declividade da encosta obtida a partir das curvas de níveis. C. Exemplo de programa na linguagem Legal para cálculo de média zonal. Grades em coordenadas UTM, zona 23, datum SAD69. 
Para obter os pesos relativos de cada indicador utilizou-se a técnica AHP - Processo Analítico Hierárquico (Marques \& Zuquette 2004; Caetano et al. 2006; Tominaga 2007). Essa técnica baseia-se na lógica da comparação pareada. Neste procedimento, os diferentes fatores que influenciam a tomada de decisão são comparados dois-a-dois, e um critério de importância relativa é atribuído ao relacionamento entre estes fatores, conforme uma escala pré-definida (Tab. 1). A partir do estabelecimento de critérios de comparação para cada combinação de fatores é possível determinar um conjunto ótimo de pesos que podem ser utilizados para a combinação dos diferentes mapas. O método foi aplicado com o uso do Software SPRING, que requer a seleção dos fatores que se deseja combinar convertidos para uma escala de [0 a 1] e a definição da importância relativa de cada um deles. O sistema fornece uma indicação da consistência do julgamento que deve ser menor que 0,1 . Como resultado, esta função do SPRING gera um modelo de programa na linguagem Legal com os respectivos pesos. A tabela 2 exemplifica a obtenção do índice de degradação, que é resultante da soma dos quatro valores normalizados dos indicadores, cada um multiplicado pelo peso obtido por meio da técnica AHP. Como descrito anteriormente, o índice de irregularidade do terreno passa por dois processos de normalização para o intervalo de $0-1$; o primeiro normaliza os resultados absolutos das linhas de quebra (m), da amplitude (m) e declividade (graus) para que seja possível calcular uma média aritmética simples entre as três variáveis (valor de 0,54 no exemplo apresentado na tabela 2). Essa média passa então por um segundo processo de normalização, no qual os valores obtidos são recalculados novamente para o intervalo de 0 -1 conforme a equação 1 (valor de 0,71 no exemplo apresentado na tabela 2) para que o índice de irregularidade possa ser comparado com os demais indicadores na mesma escala de valores.

Tabela 1 - Aplicação da técnica AHP para definição dos pesos entre os indicadores (processos erosivos, irregularidade do terreno, solo exposto, vegetação arbustiva/herbácea).

\begin{tabular}{l|l|l|l}
\hline Critério & \multicolumn{2}{l|}{ Peso } & Critério \\
\hline Processos erosivos & 2 & Um pouco melhor & Irregularidade do terreno \\
\hline Processos erosivos & 3 & Algo melhor & Solo exposto \\
\hline Processos erosivos & 6 & Bem melhor & Vegetação arbustiva/herbácea \\
\hline Irregularidade do terreno & 3 & Algo melhor & Solo exposto \\
\hline Irregularidade do terreno & 4 & Moderadamente melhor & Vegetação arbustiva/herbácea \\
\hline Solo exposto & 2 & Um pouco melhor & Vegetação arbustiva/herbácea \\
\hline Razão de consistência: 0,017 & & \\
\hline
\end{tabular}

Pesos calculados: Processos erosivos=0,482; Irregularidade do terreno=0,309; Solo exposto=0,135; Vegetação arbustiva/herbácea $=0,074$

Tabela 2 - Exemplo de cálculo do índice de degradação para a área RM-368 (figuras 3A e 4A).

\begin{tabular}{|c|c|c|c|c|c|c|c|}
\hline Indicador & Parâmetro medido & Valor absoluto & $\begin{array}{l}\text { Valor } \\
\text { normalizado }\end{array}$ & $\begin{array}{l}\text { Valor } \\
\text { médio }\end{array}$ & $\begin{array}{l}\text { Valor final } \\
\text { normalizado }\end{array}$ & Peso & $\begin{array}{l}\text { Índice } \\
\text { degradação }\end{array}$ \\
\hline $\begin{array}{l}\text { Processos } \\
\text { erosivos }\end{array}$ & Linhas de erosão & $579,40 \mathrm{~m}$ & 1,00 & & 1,00 & 0,482 & \multirow{6}{*}{$\begin{array}{l}(1 \times 0,482)+ \\
(0,71 \times 0,309)+ \\
(0,23 \times 0,135)+ \\
(0,46 \times 0,074) \\
=0,77\end{array}$} \\
\hline \multirow{3}{*}{$\begin{array}{l}\text { Irregularidade } \\
\text { do terreno }\end{array}$} & Amplitude & $60,00 \mathrm{~m}$ & 0,23 & \multirow{3}{*}{0,54} & \multirow{3}{*}{0,71} & \multirow{3}{*}{0,309} & \\
\hline & Declividade média & $22,70^{\circ}$ & 0,64 & & & & \\
\hline & $\begin{array}{l}\text { Linhas de quebra } \\
\text { de taludes }\end{array}$ & $1.149,29 \mathrm{~m}$ & 0,75 & & & & \\
\hline Solo exposto & Área & $19.794,59 \mathrm{~m}^{2}$ & 0,23 & & 0,23 & 0,135 & \\
\hline Vegetação & Área & $50.838,84 \mathrm{~m}^{2}$ & 0,46 & & 0,46 & 0,074 & \\
\hline
\end{tabular}


RESULTADOS Para as 116 áreas mineradas cadastradas foi aplicado o método de quantificação da degradação descrito anteriormente. A figura 5 e a tabela 3 mostram os resultados obtidos em histogramas com valores absolutos e dados estatísticos para as variáveis analisadas: processos erosivos, declividade média, amplitude, linhas de quebra de taludes, solo exposto, cobertura vegetal herbácea e/ou arbustiva e área total.

Os resultados, obtidos com base em ortofotos de 2001, mostram que foram registrados um total de cerca de $10 \mathrm{~km}$ de feições lineares de processos erosivos associados a áreas mineradas em Ubatuba (Fig. 5A, Tab. 3), relacionadas a cerca de $1,2 \mathrm{~km}^{2}$ de solo exposto (Fig. 5F, Tab. 3). O total de área desmatada com cobertura vegetal herbácea e/ou arbustiva associada às áreas mineradas atinge $2,4 \mathrm{~km}^{2}$ (Fig. 5G, Tab. 3). O comprimento de quebras de taludes (cortes, cavidades e irregularidade em geral), quantificadas por meio de linhas, atinge cerca de $30 \mathrm{~km}$ (Fig. 5D, Tab. 3). A declividade média das encostas, onde foram desenvolvidas as atividades de extração mineral situa-se em torno de $19^{\circ}$ e mostra uma distribuição normal no histograma (Fig. 5B). A amplitude média da encosta situa-se em torno de 50m (Fig. 5C, Tab. 3). Esses três últimos parâmetros geraram o índice irregularidade do terreno (Fig. 5E). A figura 5 e a tabela 3 mostram também os dados de área total (Fig. 5H, Tab. 3), compostos pela soma das áreas de solo exposto e cobertura vegetal.

A figura 6 mostra a distribuição em histograma do índice de degradação, os dados estatísticos e a divisão em cinco classes de degradação: muito baixa, baixa, média, alta e muito alta. Os limites das classes foram definidos pelo método do quantil, que gera $n$ grupos (classes) contendo o mesmo número de objetos em cada grupo. Assim, a classe muito alta reúne as 22 áreas mais degradadas, que constituem as áreas prioritárias para a elaboração de projetos de recuperação. A figura 7 mostra a distribuição espacial dos pontos no município. As áreas mineradas são mais freqüentes nas regiões sul e central do município, que mostram também os maiores índices de degradação em comparação com a região norte.
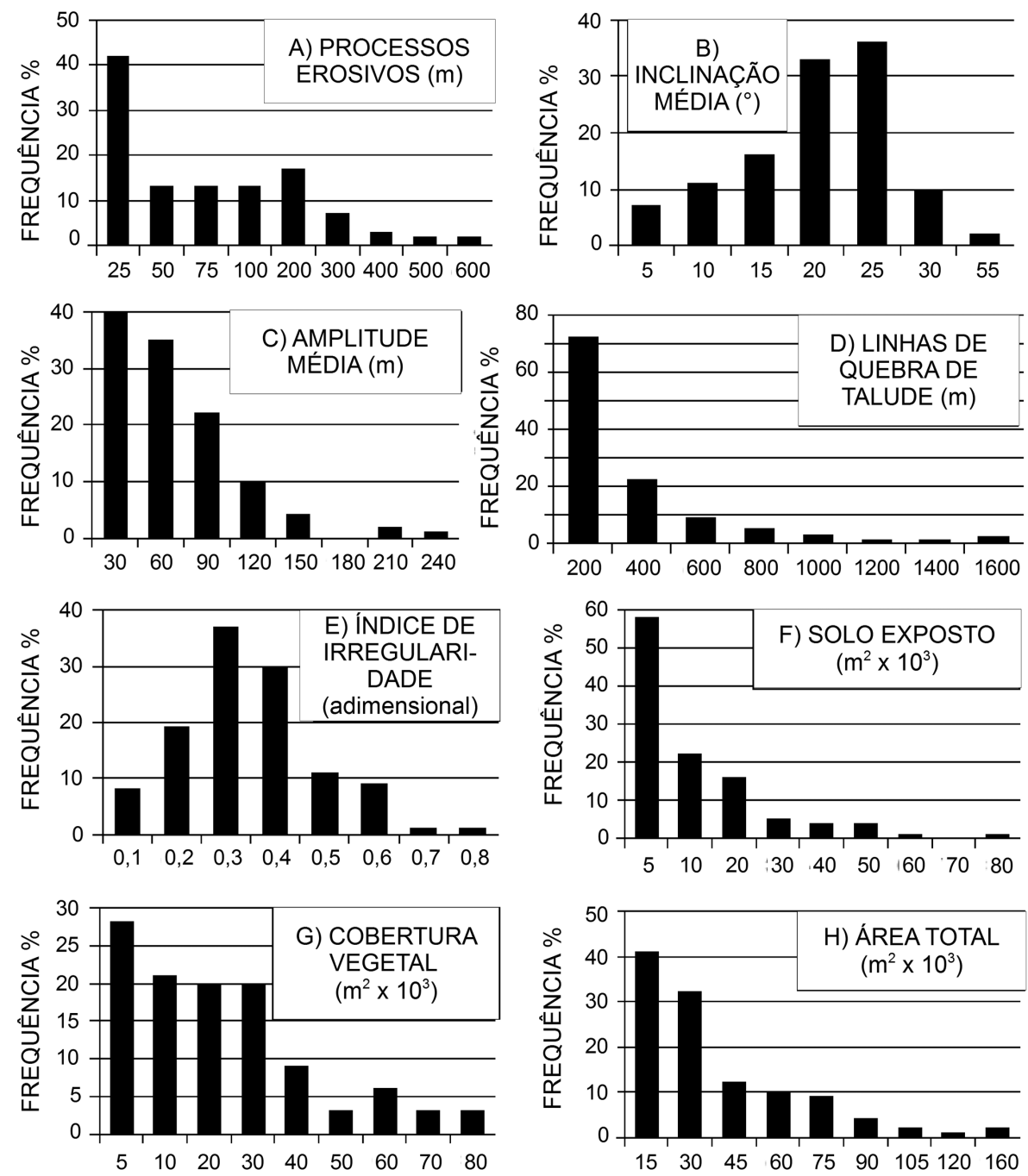

Figura 5 - Distribuição em histograma dos indicadores utilizados na obtenção do indice de degradação. 
Tabela 3 - Dados estatísticos das variáveis analisadas para definição dos índices e indicadores da degradação.

\begin{tabular}{|c|c|c|c|c|c|c|c|}
\hline & \multirow{2}{*}{$\begin{array}{l}\text { Processos } \\
\text { erosivos }(\mathrm{m})\end{array}$} & \multicolumn{3}{|c|}{ Irregularidade do terreno } & \multirow{2}{*}{$\begin{array}{l}\text { Solo } \\
\text { exposto }\left(\mathrm{m}^{2}\right)\end{array}$} & \multirow{2}{*}{$\begin{array}{l}\text { Cobertura } \\
\text { vegetal }\left(\mathrm{m}^{2}\right)\end{array}$} & \multirow{2}{*}{$\begin{array}{l}\text { Área } \\
\text { total }\left(\mathrm{m}^{2}\right)\end{array}$} \\
\hline & & $\begin{array}{l}\text { Quebras do } \\
\text { talude (m) }\end{array}$ & $\begin{array}{l}\text { Declividade } \\
\left({ }^{\circ}\right)\end{array}$ & $\begin{array}{l}\text { Amplitude } \\
\text { (m) }\end{array}$ & & & \\
\hline $\mathrm{N}^{\mathrm{o}}$ de amostras & 116 & 116 & 116 & 116 & 116 & 116 & 116 \\
\hline $\mathrm{N}^{\mathrm{o}}$ de ausentes & 0 & 0 & 0 & 0 & 0 & 0 & 0 \\
\hline Mínimo & 0,00 & 0,00 & 0,44 & 0,00 & 0,00 & 127,23 & 864,04 \\
\hline Mediana & 53,85 & 162,34 & 19,25 & 44,59 & $4.219,48$ & $12.289,23$ & $23.692,07$ \\
\hline Máximo & 579,40 & $1.539,47$ & 34,91 & 265,39 & $85.966,50$ & $110.511,11$ & $152.798,75$ \\
\hline Soma & $9.926,58$ & $31.261,73$ & - & - & $1.231 .579,26$ & $2.414 .024,18$ & $3.645 .603,44$ \\
\hline Média & 85,57 & 269,49 & 18,58 & 53,11 & $10.617,06$ & $20.810,55$ & $31.427,61$ \\
\hline Desvio-padrão & 109,78 & 300,29 & 6,68 & 41,74 & $15.714,23$ & $21.797,01$ & $29.059,62$ \\
\hline Coeficiente de variação & 1.28 & 1,11 & 0,35 & 0,78 & 1,48 & 1.04 & 0.92 \\
\hline
\end{tabular}

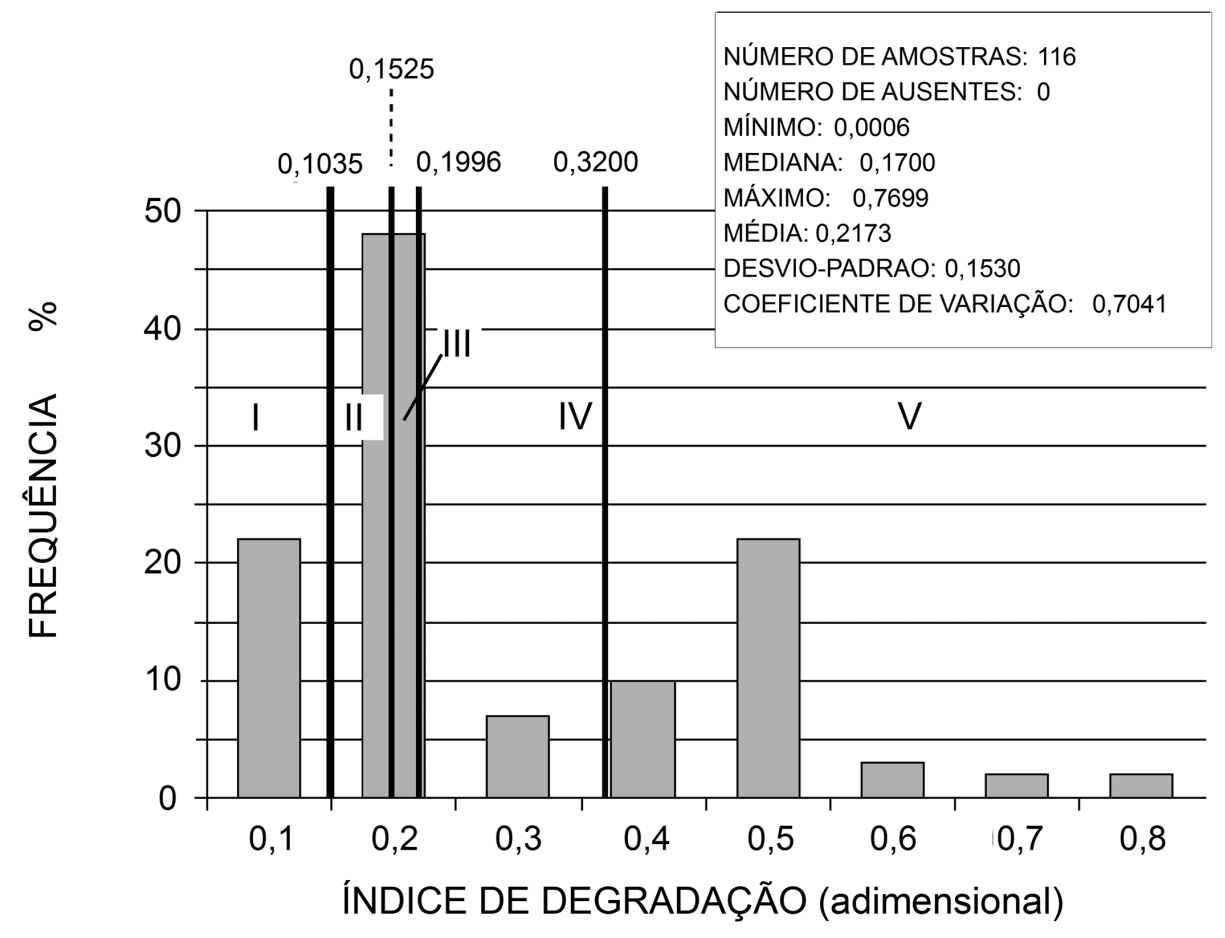

Figura 6 - Distribuição em histograma e dados estatísticos do indice de degradação. Os limites das classes foram definidos pelo método do quantil em cinco grupos e também estão discriminados na figura: I- 0,00 - 0,1035 (muito baixa degradação); II- 0,1035-0,1525 (baixa degradação); III- 0,1525-0,1996 (média degradação); IV- 0,1996-0,3200 (alta degradação); V- 0,3200-0,7699 (muito alta degradação). 


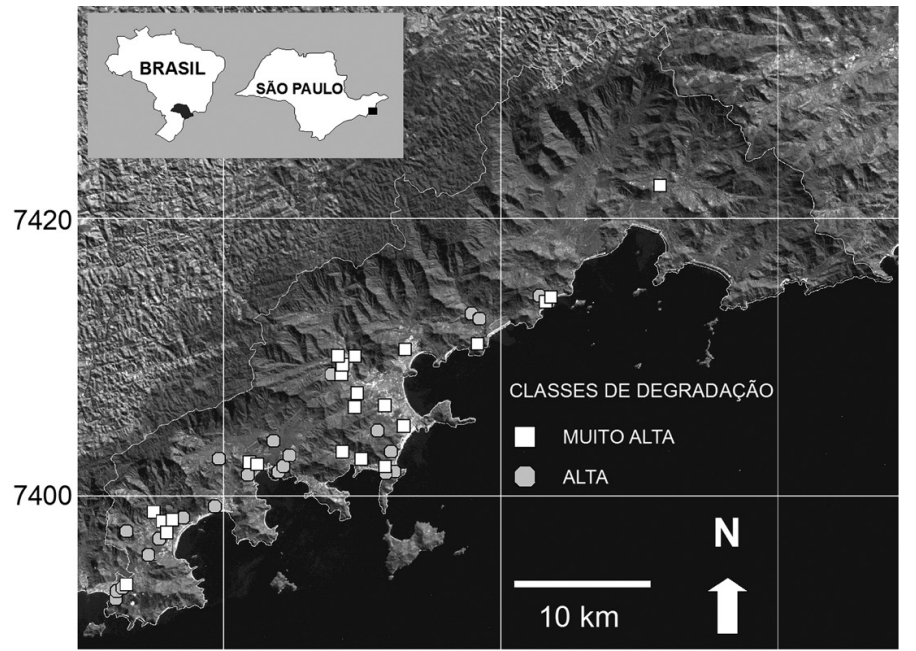

480
500
520

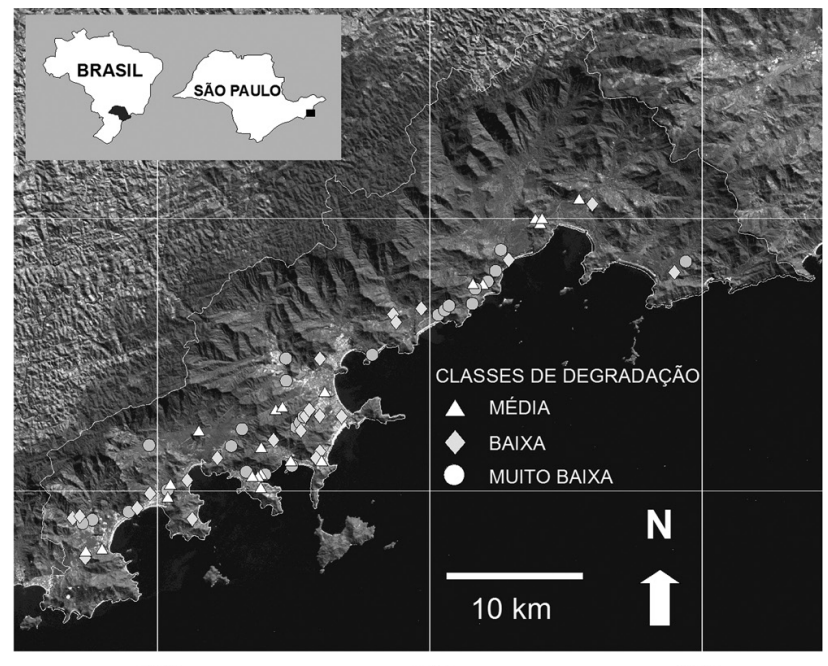

480
500
520

Figura 7 - Distribuição espacial dos pontos de mineração classificados pelo método de quantil em cinco classes conforme os intervalos do indice de degradação. Grade em UTM, zona 23, datum SAD69.

CONSIDERAÇÕES FINAIS A análise das áreas degradadas pela mineração de saibro em Ubatuba vem sendo aprimorada desde Brollo et al. (2005) e Ferreira et al. (2006b). Inicialmente a caracterização da degradação foi realizada em 95 áreas, com base em investigações expeditas de campo. Estas enfocaram principalmente aspectos cênicos, ambientais (como a remoção de vegetação e exposição do solo) e a estabilidade geotécnica, sendo diferenciadas quatro classes: recuperadas, parcialmente recuperadas, em redesenvolvimento, degradadas. Estas mesmas áreas foram classificadas quanto à estabilidade geotécnica em três classes: estáveis, em situação de instabilidade, áreas de risco. Posteriormente os estudos buscaram uma maior abrangência para a classificação das áreas degradadas no município de Ubatuba, com a análise integrada de cinco atributos (grau de degradação, ocupação atual, dimensão da área, intensidade dos perigos, risco) e a obtenção, a partir de regras matriciais, de quatro classes de degradação: muito alta, alta, média e baixa.

No presente artigo há um maior detalhamento do tema com a classificação das 116 áreas mineradas cadastradas em Ubatuba, em termos de um índice numérico, calculado com base em quatro indicadores de degradação (processos erosivos, irregularidade do terreno, área de solo exposto, área desmatada coberta por vegetação herbácea e arbustiva), culminando em cinco classes: muito baixa, baixa, média, alta e muito alta.

A escolha dos indicadores da degradação relacionou-se, nesse caso, diretamente com o processo degradador, ou seja, a extração de saibro. Considerando um modelo hipotético de evolução da extração de saibro, a primeira etapa desse processo é o desmatamento da encosta, como realmente ocorreu em muitos casos em Ubatuba, onde a mineração foi causadora inicial do desmatamento de mata primária. Assim, como indicador desse processo foi escolhida a extensão em área da ocorrência de vegetação arbustiva e herbácea relacionada à atividade de mineração.

A segunda etapa, na extração de saibro, é a escavação da encosta e retirada de material, o que provoca a eliminação da cobertura vegetal herbácea e a exposição de solo e saprolito. Na continuidade do processo extrativo ocorrem alterações da geometria da encosta, com a construção de bermas e taludes, com regularidade e padrões construtivos muito variáveis. Em muitos casos a explotação foi extremamente predatória, o que ocasionou a formação de taludes íngremes e irregulares, cavidades e ondulações na encosta. Como indicadores diretos desses processos foram escolhidos a área de solo exposto presente em cada sítio e a irregularidade do terreno. Este último é função da extensão das quebras de relevo construído na praça de lavra, bem como cavidades e ondulações do terreno, acrescido da influência da amplitude do sítio e da declividade. A amplitude e a declividade foram consideradas, pois elas dão a dimensão vertical do sítio degradado em complementação aos indicadores horizontais de área.

Concomitantemente ou após o abandono das atividades de mineração, sob controle das áreas de solo exposto e da geometria final do sítio minerado (função da amplitude e declividade) instalam-se processos erosivos com intensidade variável, que acentuam ainda mais o desequilíbrio ambiental. O indicador "processos erosivos" reflete essa etapa.

A forma de extração mineral e os processos instalados após o abandono da área geraram uma série de conseqüências que também são indicadoras da degradação, tais como, alagamento, assoreamento de cursos d'água, corrida de lama, enchente, encurvamento da encosta, abandono de equipamentos e estruturas, erosão, escoamento desordenado das águas superficiais, escorregamento, perda da camada de solo superficial, turbidez e alteração da acidez das águas, impacto visual pela degra- 
dação da paisagem, queda e rolamento de blocos, rastejo da encosta, surgência de água, geometria inadequada do talude, entre outros. No entanto, os quatro indicadores escolhidos apresentam como vantagens, em relação a indicadores mais complexos, a simplicidade de obtenção e de monitoramento, o que torna viável uma aquisição precisa e homogênea em toda a amostra (116 sítios minerados) e por refletir adequadamente o processo de extração mineral. Deste processo resultou a hierarquização de 22 áreas classificadas com muito alto índice de degradação, consideradas prioritárias para a recuperação.

O conjunto destas análises permitirá que as políticas públicas regionais e municipais (Plano Estadual de Gerenciamento Costeiro, Plano de Bacia Hidrográfica, Projeto Orla, Plano Diretor de Mineração, Plano Diretor Municipal, entre outros) incorporem tanto o processo de monitoramento dos indicadores, quanto os resultados das análises, aperfeiçoando o processo de decisão no que tange à recuperação das áreas degradadas em Ubatuba.

Agradecimentos Os autores gostariam de agradecer à pesquisadora científica do Instituto de Botânica, Elisabete Aparecida Lopes pelo auxílio em trabalhos de campo e a FAPESP pelo suporte financeiro (processo 03/07182-5).

\section{Referências}

Berger A., Satkunas J., Hermelin M. 2003. Los geoindicadores, uma necesidad para Colombia. Gaceta Academia Colombiana de Ciencias Exactas, Físicas y Naturales, VII(10):1-5.

Berger A.R. \& Iams W.J. 1996. Geoindicators: assessing rapid environmental changes in earth systems. Balkema/ Totterdam, Brokfield, 446p.

Bitar O.Y. 1990. Mineração e usos do solo no litoral paulista: estudo sobre conflitos, alterações ambientais e riscos. Dissertação de Mestrado, Instituto de Geociências, Universidade Estadual de Campinas. Campinas, 162p.

Bitar O.Y. \& Ceneviva L.L.V. 2003. O uso de indicadores ambientais em gestão ambiental municipal: o caso do município de São Paulo, SP. São Paulo. In: ABGE, Simpósio sobre Gestão Ambiental, Anais, CDROM.

Bitar O.Y., Campos H.C.N.S., Lemos A.C.P.N. 1985. Planejamento e manejo minerário municipal - a experiência no município de Ubatuba. In: SBG-SP, Simp. Reg. Geol., 5, São Paulo, Atas, v. 1, p. 99-114.

Braga T.O., Fornasari Filho N., Soares P.V. 1991. Abordagem ambiental sobre a atividade de mineração na Carta Geotécnica do município de Ubatuba-SP. In: SBG-SP, Simp. Geol. Sudeste, 6, São Paulo, Atas, p. 353-359.

Brollo M.J. 2001. Metodologia automatizada para seleção de áreas para disposição de resíduos sólidos. Aplicação na Região metropolitana de Campinas (SP). Tese de Doutoramento, Faculdade de Saúde Pública, USP, São Paulo, 212p.

Brollo M.J., Barbosa J.M., Rocha F.T., Martins S.E. 2002. Programa comum de pesquisa em caracterização e recuperação de áreas degradadas. In: CINP/SMA, Reunião Anual sobre Pesquisa Ambiental a Pesquisa Científica e Tecnológica e a Gestão Ambiental, 5, São Paulo, Anais, p. 74-82.

Brollo M.J., Ferreira C.J., Fernandes-da-Silva P.C., Tominaga L.K., Vedovello R., Guedes A.C.M., Lopes E.A., Oliveira A.R., Ummus M.E., Cripps J.C. 2005. Caracterização das áreas degradadas por mineração de saibro em Ubatuba: condicionantes para a sua recuperação ambiental. In: ABGE, Congresso Brasileiro de Geologia de Engenharia e Ambiental, 11, Florianópolis, Anais, CD-ROM.

Caetano N.R., Ohara T., Mattos J.T., Jimenéz-Rueda J.R. 2006. Carta de Aptidão para a implantação de rodovias e avaliação de alternativas de traçado com uso de geotecnologias. Revista Solos e Rochas, 29(1):17-31.

Câmara G., Souza R.C.M., Garrido J. 1996. SPRING: Integrating remote sensing and GIS by object-oriented data modelling. Computers \& Graphics, 20(3):395-403.

Campagnoli F. 2002. A aplicação do assoreamento na definição de geoindicadores ambientais em áreas urbanas: exemplo na Bacia do Alto Tietê, SP. Tese de Doutoramento, Escola Politécnica, USP, São Paulo, 195p.

Cendrero A., Francés A., Del Corral D. 2004. Environmental quality indices: a tool for assessing and monitoring geoenvironmental map units. São Carlos, SP. In: ABGE, Simpósio Brasileiro de Cartografia Geotécnica e Geoambiental, 5, São Carlos, Anais, p. 525-564.

Chieregati L.A. \& Macedo A.B. 1982. Economia mineral das rochas ornamentais. In: SBG, Congr. Bras. Geol., 32, Salvador, Anais, v.3, p. 1191-1198.

Cunha F.L.S.J. 2003. O uso de indicadores de sustentabilidade ambiental no monitoramento do desenvolvimento agrícola. Dissertação de Mestrado, Universidade de Brasília, 85p.

Degiovanni S. 2005. River response to environmental changes: monitoring of geoindicators in representative reaches of Chocancharava and Achiras-del Gato streams, Córdoba, Argentina. In: ICSU Dark Nature meeting "Holocene environmental catastrophes in South America", Laguna Mar Chiquita, Cordoba Province, Argentina, Abstracts, $1 \mathrm{p}$.

Diniz N.C., Souza N.M., Coronado J. 2005. Mapeamento geoambiental e aplicação de geoindicadores: fundamentos para um sistema de dados georeferenciados brasileiro. In: ABGE, Congresso Brasileiro de Geologia de Engenharia e Ambiental, 11, Florianópolis, Anais, CDROM.

Ferreira C.J. 2006. Hazards related to small mining of minerals for use in construction (sand, stone and residual soil) in the North Coast of State of Sao Paulo, Brazil. In: Swiss Federal Research Institute WSL, International Disaster Reduction Conference. Birmensdorf and Davos, Proceedings, v. 1. p. 250-250.

Ferreira C.J., Bérgamo T.R., Nery T.D. 2006a. Quantificação da degradação devido à extração de saibro em São Sebastião, Estado de São Paulo. In: Prefeitura Municipal de 
Ilha Comprida e Instituto de Botânica, Simpósio Regional de Recuperação de Áreas Degradadas das Formações Litorâneas, 2, Ilha Comprida, SP. Boletim de Resumos, CD-ROM, 1p.

Ferreira C.J., Fernandes-da-Silva P.C., Brollo M.J., Cripps J.C. 2006b. Dereliction problems from exploitation of residual soil and Dereliction problems from exploitation of residual soil and ornamental stone at Ubatuba, São Paulo State, Brazil. In: The Geological Society of London, IAEG Congress, $10^{\text {th }}$, Nottingham, PreCongress Proceedings, CDROM, paper 146.

Ferreira C.J., Fernandes-da-Silva PC., Furlan S.A., Brollo M.J., Tominaga L.K., Vedovello R., Guedes A.C.M., Ferreira D.F., Eduardo A.S., Azevedo Sobrinho J.M., Lopes E., Cripps J.C., Peres F., Rocha G. 2005. Devising strategies for reclamation of derelict sites due to mining of residual soil (Saibro) at Ubatuba, North Coast of Sao Paulo State, Brazil: the views and roles of stakeholders. Sociedade \& Natureza, Special Issue (ISSN 0103-1570): 643-660.

Fidalgo E.C.C. 2003. Critérios para a análise de métodos e indicadores ambientais usados na etapa de diagnóstico de planejamentos ambientais. Tese de Doutorado, Faculdade de Engenharia Agrícola, UNICAMP, Campinas, SP, 239p.

INSTITUTO BRASILEIRO DE GEOGRAFIA E ESTATÍSTICA (IBGE) 2006. Estimativas de população. Disponível em: http://www.ibge.gov.br/. Acessado em: 01/02/2006.

Marques G.N. \& Zuquette L.V. 2004. Aplicação da Técnica AHP para seleção de áreas para aterros sanitários - Região de Araraquara (SP), Brasil. In: Pejon O. \& Zuquette L.V. (eds.) Simpósio Brasileiro de Cartografia Geotécnica e Geoambiental, 5, São Carlos, SP, p. 263-272.

Rego Neto C.B. 2003. A integração de geoindicadores e reparcelamento do solo na gestão ambiental urbana. Tese de Doutorado, Universidade Federal de Santa Catarina, Florianópolis, SC, 231p.

Sánchez L.E. 1998. A desativação de empreendimentos industriais: um estudo sobre o passivo ambiental. Tese de Livre Docência, Escola Politécnica, USP, São Paulo, $178 \mathrm{p}$.

FUNDAÇÃO SISTEMA ESTADUAL DE ANÁLISE DE DADOS) (SEADE). 2006. Memória das Estatísticas Demográficas. Disponível em: http://seade.gov.br. Acessado em: 01/02/2006.

Segnestam L., Winograd M., Farrow A. 2000. Desarrollo de Indicadores. Lecciones Aprendidas de América Central. Proyecto CIAT-Banco Mundial-PNUMA, CIAT. Disponível em: http://www.ciat.cgiar.org/indicators/indicadores/toolkit.htm. Acessado em 01/03/2006.

Silva F.L.M. 1995. O risco geológico associado à ocupação de áreas de mineração no município de Ubatuba (SP). Dissertação de Mestrado, Instituto de Geociências, UNICAMP, 80p.

Silva F.L.M. \& Martins, L.A.M. 1997. Risco geológico associado à ocupação de áreas de mineração no município de Ubatuba (SP). In: SBG-SP/RJ/ES, Simp. Geol. Sudeste, 6, Itatiaia, RJ, Atas, p. 309-310.

Tominaga L.K. 2007. Avaliação de metodologias de análise de risco a escorregamentos: aplicação de um ensaio em Ubatuba, SP. Tese de Doutoramento, Faculdade de Filosofia, Letras e Ciências Humanas, USP, 220p, anexos.

Zuquette L.V., Pejon O.J., Collares J.Q.S. 2004. Land degradation assessment base on environmental geoindicators in the Fortaleza Metropolitan Region, State of Ceara, Brazil. Environmental Geology, 45:408-425.

Manuscrito ID 9853

Submetido em 27 de novembro de 2007 Aceito em 15 de junho de 2008 Sistema eletrônico de submissão 